\title{
Recursos informacionais para o ensino fundamental
}

\section{Bernadete Santos Campello Paulo da Terra Caldeira Aparecida Imaculada Bedeti da Silva Manuel Valente Mangue}

\section{INTRODUÇÃO}

A utilização efetiva de técnicas didáticas que propiciem a aprendizagem com significado é o grande desafio que, há algum tempo, tem sido colocado para os educadores. Isto significa a busca de meios que permitam uma aprendizagem profunda e consistente, ou seja, que perdure por toda a vida do educando e que, ao mesmo tempo, o habilite a pensar criticamente, preparando-o para viver em uma sociedade cada vez mais complexa.

A inadequação do positivismo como base filosófica e metodológica para a prática educacional nesta sociedade complexa é óbvia. Apesar disso, muitos professores ainda hoje utilizam exclusivamente, como técnica de ensino, as aulas expositivas que, centradas no professor, representam a aplicação prática do referido método.

"Basicamente, então, poderíamos dizer que o grande problema da metodologia expositiva, do ponto de vista pedagógico, é seu alto risco de não aprendizagem, justamente em função do baixo nível de interação sujeitoobjeto de conhecimento, ou seja, o grau de probabilidade de interação significativa é muito baixo. Pode acontecer de o aluno ouvir uma exposição e de fato aprender? Sim, mas a probabilidade é muito pequena. Este baixo nível de interação entre educador-educando-objeto de conhecimento ocorre tanto na interação objetiva (contato com o objeto, manipulação, experimentação, forma de organização da coletividade de sala de aula etc.), quanto na interação subjetiva (reflexão do sujeito, problematização, estabelecimento de relações mentais, análise, síntese etc.).
Do ponto de vista político, o grande problema da metodologia expositiva é a formação do homem passivo, não crítico, bem como o papel que desempenha como fator de seleção social, já que apenas determinados segmentos sociais se beneficiam com seu uso pela escola (notadamente a classe dominante, acostumada ao tipo de discurso levado pela escola, assim como ao pensamento mais abstrato)." (VasconceIlos, 1992).

A aprendizagem resultante da aplicação do método é superficial e útil apenas para resolver um problema imediato, como, por exemplo, passar no vestibular.

O grande número de crianças e jovens que precisam se preparar para serem cidadãos críticos e conscientes, capazes de contribuir para a construção de uma sociedade democrática, pressupõe a aplicação adequada de considerável volume de recursos na educação. Em última instância, isso só ocorrerá se Ihes for propiciada uma educação de qualidade, consistente e duradoura.

A maioria da população brasileira só é envolvida no processo educacional formal nas primeiras séries do ensino fundamental, confirmando, portanto, a necessidade urgente de se aproveitar esse curto período para o desenvolvimento de habilidades e atitudes adequadas, que acompanhem o educando pelo resto da vida, permitindo a sua inserção positiva na sociedade contemporânea. 
A aprendizagem com significado, duradoura e profunda é, sem dúvida, aquela centrada no aluno, envolvendo mais do que simples aulas expositivas, livros-textos, apostilas ou pesquisas copiadas de enciclopédias. Envolve principalmente "o direito de discordar, o direito de questionar, o direito de opinar." (Falcão Filho, 1988). Para tanto, é preciso abrir para os alunos um leque de recursos informacionais, suficientemente amplo para despertar sua curiosidade e permitir a problematização. É neste processo de problematização de situações e de busca de soluções, com orientação adequada, que está centrada a aprendizagem duradoura.

As técnicas de ensino voltadas para a repetição de conceitos supostamente verdadeiros não são suficientes para preparar os alunos para a chamada sociedade da informação, na qual as exigências são baseadas na capacidade de utilização adequada dos amplos e complexos recursos informacionais disponíveis. Assim sendo, quanto mais cedo a criança for exposta a esses recursos, de maneira sistematizada, mais condições terá de utilizá-los adequadamente e de maneira crítica.

Uma tarefa comum na escola fundamental, que implica necessariamente a utilização de recursos informacionais, é o trabalho de pesquisa escolar. Concebida originalmente como instrumento para a aprendizagem por descoberta, processo pelo qual o aluno vai construindo seu próprio caminho para o conhecimento, sob orientação de agentes educacionais, a pesquisa escolar resvalou, ao longo dos anos, para a cópia literal e indiscriminada de textos, a tal ponto que, hoje, suscita reclamações de todos nela envolvidos. Assim, os professores lamentam que os alunos não se interessam por materiais escritos, detestam ler, limitam-se a copiar parágrafos de enciclopédias em suas pesquisas escolares; os alunos reclamam que os textos são difíceis e chatos, sem qualquer interesse; na biblioteca, o bibliotecário se preocupa com a pouca e má utilização do material informativo adquirido com dificuldade e organizado para atendimento dos usuários; isso sem mencionar os pais dos alunos, desorientados diante das instruções - mais ainda da falta delas - para a elaboração dos trabaIhos escolares.
Uma das características mais marcantes da sociedade contemporânea é justamente a sua capacidade de produção de informações, não só em quantidade, mas também em variedade de formas e opções. O material impresso, que durante muitos anos constituiu o único material utilizado no processo de aprendizagem, passa a ser complementado por tecnologias avançadas que privilegiam a imagem e o som. A complexidade do ambiente informacional aumenta se forem levados em conta os equipamentos necessários à utilização dos recursos.

Do ponto de vista prático e operacional, esses recursos devem ser localizados de forma a estarem disponibilizados para todos os usuários. A sua utilização efetiva pressupõe uma adequação à faixa etária e nível de compreensão do aluno, atualização constante, além de orientação individualizada e planejada. Isto significa que há necessidade de um profissional que, juntamente com os professores, seja responsável por colocar o uso de informações registradas no cerne do processo ensino/aprendizagem.

Tradicionalmente, os recursos informacionais, representados geralmente por materiais impressos (livros-texto, enciclopédias, dicionários, livros de literatura) têm sido adquiridos pela escola e reunidos em local comumente chamado de biblioteca escolar. Esta tem, sobretudo, um papel pedagógico a cumprir, pois está inserida em uma unidade educacional e deve ser o espaço centralizador do acervo bibliográfico e de material especial da escola, provendo esta comunidade de suporte para realização de suas pesquisas e apoiando a reconstrução do conhecimento a partir da democratização da informação. Entretanto, estando normalmente localizada em lugares inadequados, com coleções desatualizadas e sem pessoal que possa desenvolver um trabalho planejado de utilização efetiva dos recursos informacionais, a biblioteca escolar tem tido desempenho restrito, sendo incapaz de despertar nos alunos a curiosidade e a habilidade de problematização.
Entretanto, há evidências de que os recursos informacionais disponibilizados dinamicamente têm potencial para melhorar o desenvolvimento cognitivo da criança, estimular sua capacidade de pensar criticamente e de solucionar problemas. Um dos passos para que a tradicional biblioteca escolar se transforme no ambiente dinâmico necessário à aprendizagem com significado é a identificação e conhecimento de recursos de informação adequados, que se encontram dispersos, têm formato variado e são produzidos em enorme quantidade por uma diversidade de organizações, enfim, refletindo o mundo pluralista em que vivemos.

\section{OBJETIVOS/METODOLOGIA}

A presente pesquisa objetivou identificar os recursos informacionais para o ensino fundamental produzidos no Brasil. Mais especificamente, pretendeu-se levantar - da forma o mais exaustiva possível - os produtores de materiais voltados para este segmento, incluindo materiais impressos, $c d$-rom e disquetes. Este levantamento foi feito utilizando-se diversos meios (Anexo 1).

As organizações identificadas foram caracterizadas em termos de: data de início das atividades, local da sede, filiais, tiragem média e número de títulos publicados em 1995 e planos para publicação eletrônica. Cientes de que esses produtores, em sua maioria, localizam-se na região centro-sul do país, buscou-se verificar se os mesmos procuram atingir um público mais amplo, estudando-se os processos de divulgação por eles utilizados. Para isso, foi utilizado um questionário enviado a todos os produtores identificados (Anexo 2).

Sabendo que as organizações produtoras são, na sua maioria, empresas comerciais com fins lucrativos, a pesquisa procurou verificar até que ponto estas organizações se preocupam em fornecer aos clientes informações suficientes que lhes permitam fazer uma escolha bem embasada, observandose os aspectos pedagógicos envolvidos. Isto foi feito mediante análise do material de divulgação por elas enviado, verificando-se nos catálogos a existência das seguintes informações: autores/ilustradores, série/faixa etária, 
tema/assunto, sinopse do conteúdo, recomendações para uso, foto da capa, tamanho, indicação de cores, ano de publicação, ISBN ${ }^{*}$, prêmios e indicade distribuidores. Quanto aos produtos eletrônicos, verificou-se, além desses itens, a existência de informação sobre a versão dos programas e as ferramentas disponíveis.

\section{ANÁLISE DOS DADOS}

A análise dos dados que permitiram a caracterização das organizações produtoras de recursos informacionais foi feita com base em 91 questionários respondidos, dos 208 enviados para as organizações identificadas.

O estudo do material de divulgação foi desenvolvido a partir de catálogos enviados.

\section{Características das organizações produtoras}

\section{a) Início das atividades}

A mais antiga das organizações participantes da pesquisa surgiu no ano de 1900; até a década de 40, havia dez organizações ligadas à área de recursos informacionais para o ensino fundamental no Brasil. A década de 50 presenciou 0 aparecimento de apenas duas e, na década de 60 , houve um salto significativo representado pela criação de 12 organizações. Na década de 70, surgiram dezessete. Quase a metade das 86 organizações que responderam a esta questão iniciou suas atividades nas décadas de 80 e 90 (vinte e 25 respectivamente). Verifica-se, portanto, um crescimento regular do setor, desde a década de 60 até os dias atuais, quando surgiram 74 das 86 organizações que indicaram a data de sua criação. Até então, o mercado era representado apenas por doze editoras, surgidas na proporção de uma a três por década. ções, críticas de resenhas, preço, lista

O crescimento da indústria editorial brasileira como um todo foi previsto pelo historiador britânico Lawrence Hallewell, que, em um estudo divulgado na década de 80 (Hallewell, 1982) identificou o mercado produtor do país como o de maior potencial na América Latina. As previsões de Hallewell se confirmaram, como indicado pelos dados divulgados pela Câmara Brasileira do Livro, que, em estudo encomendado à Fundação João Pinheiro de Belo Horizonte* , mostrou que o Brasil é responsável por $53 \%$ dos títulos produzidos e por $54 \%$ dos exemplares de livros vendidos na América Latina, no período 1994/1996. Neste período, o mercado brasileiro de livros cresceu $45 \%$ em exemplares vendidos e $48 \%$ em faturamento.

O subsetor de livros infantis e didáticos foi o responsável por mais da metade do mercado como um todo: dos 242 milhões de livros vendidos de janeiro a agosto de $1996,66 \%$ eram destinados a alunos em fase de alfabetização, de ensino fundamental e de $2^{\circ}$ grau. Esta tendência tem sido observada desde 1994. O subsetor infantil ficou abaixo apenas do mercado dos livros da área de religião, que cresceu cerca de $97 \%$ nos últimos dois anos, impulsionado pelo esquema de distribuição, que transforma as várias igrejas em pontos de vendas dessas publicações.

O crescimento significativo da produção editorial na década de 70 foi analisado por Alves (1982), que apontou, como causas, o aumento do número de vagas nas escolas e a implantação de programas oficiais de alfabetização que absorviam grande volume das tiragens de livros didáticos, distribuídos gratuitamente pelo governo. Em 1974, os livros didáticos representaram $47 \%$ da produção total de livros no país. Da mesma forma, a área de literatura infantil e juvenil apresentou um crescimento considerável no período 1974/1976, causado, segundo o referido autor, por programas de incentivo governamentais e pela utilização desses livros como leitura complementar no ensino fundamental. O aparecimento de um número considerável de editoras coincide, portanto, com o crescimento do volume de livros editados no período.

\footnotetext{
* Número internacional padronizado para livros.
}

Constata-se, enfim, a existência de editoras consolidadas, que se mantêm há bastante tempo no mercado, e, ao mesmo tempo, o aparecimento de novas organizações que surgem para ocupar nichos de mercados específicos, atendendo à demanda crescente por recursos informacionais educativos.

b) Local da sede

As sedes das 91 editoras que responderam à questão localizam-se em cinco estados e quatorze cidades, havendo enorme concentração no Estado de São Paulo. Este estado sedia 58 editoras, as quais estão localizadas em apenas cinco cidades paulistas, sendo que a cidade de São Paulo concentra 53 editoras, enquanto as demais, quatro, sediam uma editora cada.

Embora apareça em segundo lugar, o Rio de Janeiro sedia um número menor de editoras que São Paulo (quinze), sendo treze na capital do estado e duas em Petrópolis. Considerado por Hallewell (1982) como de importância igual a São Paulo como centro editorial naquela época (a diferença era que o Rio era mais forte em literatura, ao passo que São Paulo era considerada a cidade do livro didático), o Rio de Janeiro, no que tange à produção de livros para o ensino fundamental está mais próximo de Belo Horizonte, que sedia apenas oito editoras. O Paraná sedia cinco (quatro em Curitiba e uma em Pinhais), o Rio Grande do Sul quatro (três em Porto Alegre e uma em São Leopoldo) e uma em Brasília, DF.

A concentração do mercado consumidor é o fator responsável pelo mesmo fenômeno com relação às editoras, fato já constatado em 1955 pelo editor Enio Silveira, quando declarava que "somente as cidades de São Paulo, Rio de Janeiro, Recife, Porto Alegre, Belo Horizonte, Salvador e Curitiba (nessa ordem) é que representam positivamente o maior mercado para o livro em nosso país." (apud Hallewell, 1984, p.516). 
O potencial de Minas Gerais como mercado produtor de livros não foi bem avaliado na época. Hoje, o estado coloca-se em segundo lugar no país em número de lançamentos, perdendo apenas para São Paulo, e esta situação deve-se especialmente à produção de livros didáticos, paradidáticos e infanto-juvenis. (Mesquita, 1995).

\section{c) Filiais}

A alta concentração das sedes das editoras em estados do Sudeste já era prevista tendo em vista o desenvolvimento econômico e social da região. $O$ interesse da pesquisa era verificar se, embora concentradas regionalmente, as editoras desenvolviam ações para atingir um público mais distante.

A constatação da existência de filiais das editoras em outros estados mostrou que existe uma rede de distribuição mais ampla: as 51 editoras que responderam à questão possuem filiais em 24 cidades de 13 estados.

d) Número de títulos publicados em 1995

O número de títulos publicados em 1995 pelas 76 editoras que responderam a esta questão variou de 1200 a dois. Foram produzidos naquele ano um total de 6533 títulos: uma média de 85,9 por editora. Hallewell (1982) havia constatado, no início dos anos 80 , que, das 30 a 40 editoras brasileiras que produziam livros para crianças, apenas um terço lançava mais de dois títulos por ano.

Uma pesquisa feita em 1982, relatada pelo citado autor, verificou que o número de títulos de literatura infantil à venda em quatorze editoras variava de 270 a cinco. Embora originados de critérios diferentes dos dados do presente estudo, estes números mostram uma tendência, observada a partir da década de 70, de diversificação dos títulos e tipos de obras, causado, seja pela redução da dependência de um único livro didático para cada curso, seja pelo advento de uma diversificação regional extremamente necessária no ensino ou pelo fato de as escolas e professores estarem sendo menos conformistas em suas escolhas e, finalmente, devido à concorrência entre um número maior de editoras (Hallewell, 1982).
Das 76 editoras que forneceram este dado, 16 produziram mais de 100 títulos em 1995 (321 em média). As sessenta restantes produziram uma média de 23,8 títulos. Estes números indicam um aumento considerável na produção bibliográfica nacional relativa ao ensino fundamental.

\section{e) Tiragem média}

A tiragem média dos títulos publicados em 1995 pelas 73 editoras que forneceram este dado variou de $80 \mathrm{mil}$ a mil.

As tiragens de livros didáticos no Brasil já atingiram, ao final da década de 70, 200 mil exemplares. Entretanto, na década de 80 , já se observava um declínio neste número, resultante do aumento da variedade de títulos, como já comentado anteriormente. No início da década de 80 , segundo Hallewell (1982), as tiragens mais comuns eram de 50 mil exemplares.

Atualmente, este número está bem mais baixo, situando-se na faixa de mil a 5 mil exemplares: mais da metade das editoras pesquisadas mantém tiragens médias nesta faixa. Tiragens de mais de 30 mil exemplares só foram relatadas por três editoras; onze informaram realizar tiragens entre 10 mil e 30 mil exemplares.

O crescimento tanto de títulos produzidos quanto de exemplares vendidos, acompanhado de uma diminuição nas tiragens, confirma a tendência de diversificação que pode ser observada também no aparecimento de produtos como os livros-brinquedo e de livros mais baratos, vendidos em bancas. Isto reforça a estratégia de diversificação da indústria editorial que está atenta para atender a todas as faixas do mercado consumidor.

\section{f) Planos para publicação eletrônica}

Com o objetivo de verificar se as editoras estão também atentas para o mercado da publicação eletrônica, um segmento que deverá ter enorme expansão nos próximos anos, foi indagado se as mesmas contavam com planos para entrar neste mercado. Os resultados obtidos indicam o interesse dos editores nesse novo nicho.
Vinte e seis das 90 editoras que responderam à questão já estão neste mercado com algum produto em forma eletrônica: $C D-R O M$ ou disquete. Quarenta já têm planos semelhantes, sendo que a maioria delas está se preparando para atuar neste segmento a partir de 1997 e 1998. Apenas 24 editoras declararam explicitamente não pretenderem atuar neste filão.

\section{Divulgação}

Das 91 editoras que responderam a esta questão, a maioria informou utilizar uma variedade de meios para divulgar seus produtos, à exceção de quatro que afirmaram utilizar um único meio. É comum a participação em feiras (como a Bienal do Livro), sendo que 75 editoras utilizam estes eventos para divulgação de seus produtos.

Catálogos são utilizados por 75 editoras, seguidos de folders, usados por 57. Publicidade na mídia, em congressos, em seminários e visitas de promotores são formas freqüentemente utilizadas como meio de divulgação. Menos freqüentes são o telemarketing e outros meios não identificados. A Internet surge também como um veículo de divulgação no meio editorial: das 107 editoras incluídas no guia Recursos informacionais para o ensino fundamental: guia de produtores, ${ }^{*}$ quinze têm sites na Internet.

a) Publicidade nos meios de comunicação de massa

A publicidade das editoras feita pelos meios de comunicação de massa está distribuída entre os seguintes veículos: revistas (utilizadas por 50 editoras), jornais (47), rádio (23), televisão (13) e outdoors (5). Estes veículos parecem atingir grande e diversificado público, embora não se tenha uma confirmação de sua eficácia.

\footnotetext{
* Este guia, publicado em 1997, constitui um subproduto da pesquisa e inclui 107 editoras com seus respectivos endereços e linhas editoriais.
} 


\section{b) Âmbito da divulgação}

A maioria das editoras não restringe sua divulgação a um só estado ou região: 75 declaram divulgar seus produtos para todo o país. Poucas (11) buscam atingir o mercado internacional, divulgando suas publicações e produtos em países da América Latina (Argentina, Bolívia, Colômbia, Paraguai e Uruguai), México, Portugal e Estados Unidos. Duas instituições informaram que enviam participantes a feiras internacionais.

\section{c) Divulgação de catálogo e folder}

O catálogo, que é um meio de divulgação tradicional das editoras, é enviado, principalmente, para as escolas. Das 79 editoras que responderam a esta questão, 67 adotam este procedimento. Um número significativo de editoras (45) envia seus catálogos para pessoas físicas, contrastando com a quantidade que declarou enviá-los para bibliotecas (apenas 8).

Constata-se, portanto, a permanência de uma situação já observada de longa data: as bibliotecas não fazem parte do mercado consumidor de livros no Brasil.

No caso do folder, repete-se o padrão encontrado na divulgação do catálogo. A maioria das editoras (55 das 67 que forneceram este dado) preocupa-se em encaminhá-los para as escolas. Há, também, um número significativo de organizações que endereça este tipo de divulgação para pessoas físicas (39) e, também aqui, o envio para bibliotecas é quase nulo (6).

Como a maioria das distribuidoras recebe os catálogos (66) e folders (45) de suas editoras e não lhes foi perguntado como são redistribuídos, pode haver uma diferença no universo dos consumidores que os recebem.

\section{Características do material de divulgação}

Para esta análise, os materiais de divulgação foram divididos em dois grupos - materiais impressos (76) e materiais eletrônicos (15) -, tendo em vista suas especificidades. Deve-se destacar que, entre os 76 catálogos de material impressos, quatro deles incluem materiais eletrônicos, perfazendo o total de 15.

\section{Material de divulgação de publicações impressas}

\section{a) Autores/ilustradores}

Informações sobre autores são de fundamental importância para permitir a avaliação da qualidade do material. Entretanto, os catálogos apresentam apenas o nome dos autor(es), omitindo, na maioria das vezes, dados biográficos e atividades profissionais que exercem. Esses dados apareceram com pouca freqüência nos 76 catálogos analisados: apenas 15 deles as incluíam. Mesmo assim, três dos que incluíram informação sobre autores o fizeram de forma parcial, isto é, forneceram apenas alguns dados dos autores. Os nomes dos ilustradores (dado de enorme importância no caso em estudo) foram mencionados em 41 dos 76 catálogos embora se esperasse maior importância por parte dos editores a esse aspecto.

\section{b) Série/faixa etária}

A indicação da série e faixa etária no material de divulgação é fundamental, sobretudo para os professores, uma vez que cada aluno possui um ritmo próprio de desenvolvimento escolar e, por isso, esforços devem ser feitos para considerar esse aspecto no sentido de facilitar a seleção dos livros mais adequados para o nível de cada leitor.

Informações sobre série e faixa etária contidas nos 76 catálogos analisados não são muito precisas. A análise mostrou que 38 catálogos indicaram a série das publicações. Destes, quatro não citaram especificamente a série, mas o nível de escolaridade (por exemplo: $1^{\circ}$ grau). Um catálogo de uma editora não apresenta essa informação para todas as obras divulgadas.
A situação é semelhante com relação à faixa etária. Vinte e nove dos $76 \mathrm{ca}$ tálogos analisados incluem a faixa etária; cinco indicam o público a que se destina (por exemplo: infantil, juvenil etc.); quatro apresentam esse dado apenas para algumas publicações.

Duas editoras acompanharam a tendência mais moderna de trabalhar em função do nível escolar ou a experiência do educando.

c) Tema-assunto/sinopse do conteúdo

A indicação do tema/assunto tem grande importância nesse tipo de material por possibilitar a seleção de obras de acordo com o interesse do leitor. Através da análise dos 76 catálogos, percebeu-se que havia preocupação por parte de editores em indicar o tema/ assunto dos livros, seja na forma de índices ou no próprio comentário. Entre estes, apenas duas editoras forneceram esta informação sobre algumas obras.

No que se refere às sinopses do conteúdo das obras, a análise dos catálogos indicou que há uma preocupação ainda maior por parte dos editores em relação a esse quesito, pois 55 editoras apresentaram sinopse para cada livro, e apenas duas se limitaram a apresentar sinopse de toda a coleção.

\section{d) Recomendações para uso}

Apesar de ser um item fundamental para melhor aproveitamento do material produzido, poucas editoras mostraram-se preocupadas em prover os educadores e demais interessados com informações sobre a utilização desses materiais. Apenas 17 das 76 editoras apresentaram recomendações para uso; duas apresentaram propostas de atividades; uma delas, ficha de atividades. 
e) Foto da capa/número de páginas/indicação das cores

Os aspectos gráficos de uma publicação são bastante relevantes no processo de seleção, por permitirem uma visualização mais precisa da obra a ser adquirida. Considerando-se este aspecto, verificou-se que 34 catálogos apresentam a foto da capa em seu material de divulgação e 46 indicam o número de páginas da publicação. A indicação de cores, ao contrário dos itens acima, aparece em apenas 13 dos 76 catálogos analisados, sendo que cinco das organizações informam que o livro é colorido, não citando, entretanto, as cores.

\section{f) Ano de publicação/ ISBN}

A partir da análise dos 76 catálogos, percebe-se que foi dada pouca importância à indicação do ano de publicação da obra e ao ISBN. Cada um desses itens foi indicado somente por cinco organizações. Entretanto, a não-indicação do ano de lançamento pode ser explicada pela própria dinâmica de publicação de catálogos. Normalmente, eles são editados anualmente e quase sempre estampam na capa a data com grande destaque. A questão do ISBN não deve ser analisada em termos comparativos, pois não se pesquisou quais são as organizações que utilizam este sistema.

\section{g) Preço}

As organizações envolvidas com a produção de material bibliográfico e não bibliográfico destinadas ao ensino fundamental mostram uma preocupação com relação ao preço de seus produtos. Dos 76 catálogos analisados, 25 fornecem esta informação, sendo que 13 apresentam lista de preços no próprio catálogo e 12 o fazem em listas separadas. h) Lista de distribuidores

Uma parcela significativa de editoras, quase a metade das 76 , forneceu a lista de seus distribuidores com endereços; destes, dois não citaram os respectivos endereços; uma listou seus distribuidores no exterior, uma trouxe a lista das filiais e uma editora incluiu sua lista de distribuidores na lista de preços, separadamente do catálogo.

\section{i) Prêmios e indicações/críticas e resenhas}

Algumas editoras (21) destacam as obras premiadas, indicadas ou recomendadas por instituições como a Fundação Nacional do Livro Infantil e Juvenil (FNLIJ), Ministério da Educação e Desporto (MEC) e outras. As críticas ao material na forma de resenhas em jornais e outras publicações, que poderiam conferir maior credibilidade à obra e à organização produtora, foram mencionadas em 11 dos 76 catálogos. Estes dados não permitem análise comparativa, pois não se pesquisou quais obras receberam prêmios, indicações ou recomendações e quais foram resenhadas. A sua inclusão pode constituir uma estratégia de marketing, mas não deixa de ser um ponto positivo para auxiliar na seleção.

É importante salientar alguns itens observados além daqueles preestabelecidos no estudo: percebeu-se que uma parcela significativa do material de divulgação (11) apresentam ou fazem referência às suas coleções; 13 incluem índices, de forma a facilitar a localização do material no catálogo; três indicam o número da edição; duas indicam o tipo de encadernação e o nome dos tradutores; uma preocupa-se em citar a língua original; outra fornece catálogo dos títulos recomendados pela FAE.

\section{Material de divulgação de produtos eletrônicos}

Foi analisado o material de divulgação de 15 empresas; destas, 11 apresentaram material exclusivo para divulgar produtos eletrônicos. Entre as 11, seis são empresas especializadas na produção desse tipo de recurso. Quatro incluem seus produtos eletrônicos no catálogo geral, e, destas, duas utilizam um folheto geral.

A foto da capa do produto na sua forma impressa ou eletrônica foi encontrada em 14 dos 15 catálogos analisados.

A preocupação em informar a série a que se destina pode ser percebida em sete catálogos. A indicação da faixa etária e do público a que se destina foram indicados em quatro dos materiais observados. O nome do autor/produtor foi indicado em seis catálogos, mas nenhum deles apresentou maiores informações sobre os mesmos.

O ano de publicação dos materiais impressos ou eletrônicos não foi indicado nos catálogos ou folhetos: apenas uma organização citou o ano em que o software por ela divulgado foi criado.

A indicação de preço no catálogo foi observada em cinco catálogos enquanto os preços em listas separadas apareceram em apenas dois.

O idioma dos materiais foi citado em cinco dos 15 catálogos analisados, e as críticas e resenhas, somente em dois.

A lista de distribuidores foi divulgada por seis organizações.

Atenção bem maior foi prestada aos aspectos relativos ao conteúdo dos materiais, pois, 14 catálogos oferecem sinopse do conteúdo, nove indicam o tema ou assunto tratado. Já em relação às recomendações para uso dos mesmos, ocorre situação contrária: apenas três forneceram esse dado. 
Percebe-se que, a partir da análise dos catálogos de 15 organizações, estas, em sua maioria, preocuparam-se em informar que tipo de material estão oferecendo (cd-rom, disquete ou ambos). Três oferecem disquetes, oito produzem cd-rom, uma produz cd-rom e cdplayer infantil e informou quantos cds completam a coleção.

Outros itens que não constavam dos critérios pré-definidos para análise dos catálogos foram observados e merecem destaque: quatro organizações citam a versão dos programas divulgados; duas indicam as premiações recebidas e uma ressalta as ferramentas disponíveis nos programas.

\section{CONCLUSÃO}

O segmento da indústria editorial brasileira voltado para o ensino fundamental apresenta-se com uma produção diversificada, oferecendo uma variedade de materiais típica do ambiente informacional da sociedade contemporânea. Além do livro impresso, há uma produção significativa de $C D-R O M \mathrm{~s}$, fitas cassete, disquetes, vídeos e material geográfico. Em termos de conteúdo, a maior parte das organizações envolve-se com a produção de livros didáticos, paradidáticos e literatura infantil, com uma diversificação de assuntos que contempla especialmente arte, biografia, educação ambiental e religião, além de material de referência. É um setor que se apresenta consolidado, com crescimento significativo a partir da década de 60, no que diz respeito às organizações que o compõem.
Embora apresentando um bom nível de qualidade no que diz respeito à sua aparência externa, os catálogos analisados apresentam deficiências nas informações que incluem. Com relação aos aspectos intrínsecos (dados sobre os autores e ilustradores, faixa etária e série às quais se destinam, tema, sinopse do conteúdo e recomendações para uso), apenas a indicação do tema e a sinopse aparecem em mais da metade dos catálogos. As outras informações são apresentadas de forma esporádica, indicando a pouca preocupação das organizações em fornecer dados que permitam uma seleção criteriosa. No que diz respeito aos aspectos extrínsecos (reprodução da capa, número de páginas, indicação de cores), a situação é semelhante, sendo que o único item indicado em mais da metade dos catálogos foi o número de páginas.

O crescimento da produção de recursos informacionais para o ensino fundamental no país é extremamente positivo, na medida em que possibilita maiores opções para escolha pelo leitor. O crescimento, tanto em número de organizações produtoras, quanto de material produzido, tende a ser um fator de melhoria da qualidade do produto.

Entretanto, é preciso avaliar permanentemente o que está sendo lançado no mercado; isto pode ajudar a manter a qualidade e evitar que as características extrínsecas do produto predominem sobre o conteúdo.
Por outro lado, a tímida participação da biblioteca escolar como consumidora de recursos informacionais é um fator extremamente negativo. A contradição observada (mercado editorial vigoroso, de qualidade e em crescimento versus bibliotecas com coleções pobres) já foi mencionada por Roy (1994), que analisou a questão das bibliotecas escolares na França. Capacitados profissionalmente a orientar os alunos na utilização dos recursos informacionais, os bibliotecários poderiam contribuir positivamente para o aperfeiçoamento da qualidade desses recursos. Neste sentido, é fundamental o trabalho desenvolvido por entidades como a Fundação Nacional do Livro Infantil e Juvenil (FNLIJ). Este tipo de trabalho precisa ser ampliado para atingir o mercado produtor como um todo. Aqui, o papel do bibliotecário como avaliador da qualidade do material é fundamental; por meio de suas entidades específicas, os bibliotecários que atuam em bibliotecas escolares poderiam prestar excelente contribuição ao público envolvido com a elaboração de avaliações criteriosas dos materiais que utilizam, passando, assim, sua experiência para outros colegas e contribuindo para o aperfeiçoamento da qualidade desses materiais.

Os produtores, por sua vez, devem se conscientizar sobre as peculiaridades do mercado em que atuam e produzir material de divulgação que possibilite a escolha criteriosa de seus materiais. 


\section{REFERÊNCIAS BIBLIOGRÁFICAS}

1. BREIVIK, Patricia Senn. The role of libraries in the search for educacional excelence. School Library Media Quarterly, Chicago, v.16, n.1, p.45-46, Fall 1987.

2. CARVALHO, Maria da Conceição. Indústria cultural e literatura infantil. R. Escola Bibliotecon. UFMG, Belo Horizonte, v.23, n.2, p.189-196, jul./dez. 1994

3. CLYDE, Laurel A. Computer-based resources for young people: an overview. International Review of Children's Literature and Librarianship, London, v.8, n.1, p.121, 1993.

4. DEFINIÇÃO de critérios para avaliação dos livros didáticos: $1^{\underline{a}}$ a $4^{\underline{a}}$ séries. Brasília: FAE, 1994. 376p.

5. FALCÃO FILHO, José Leão. O ensino centrado na relação professor-aluno. $R$. $P e$ dagógica, Belo Horizonte, v.6, n.33, p.5, maio/jun. 1988.

6. FOGAÇA, Francisco José. Educação: metodologia, técnica e abordagem política. $R$. Pedagógica, Belo Horizonte, v.4, n.53, p.9-11, set./out. 1991.

7. HALLEWELL, Lawrence. O livro no Brasil:sua história. São Paulo: T.A. Queiroz/EDUSP, 1982. $693 \mathrm{p}$.

8. HERRING, J. E. School librarianship. London: C. Bingley, 1982. 116p. Cap. 12: p.94-96, The future.

9. MESQUITA, Cláudia. Editoras de Minas: ainda longe da "literatura adulta". Hoje em Dia, Belo Horizonte, 25 de abril de 1995. Caderno Cultura, p.1.

10. ROY, Jean-Paul. Bibliothèques bien vivantes mais encore fragiles. Documentation et bibliothèques. Montreal, v.40, n.4, 1994. p. 187-188.

\section{Information resources for elementary education}

\section{Abstract}

This article points out the characteristics of the market of information resources for elementary education in Brazil. It identifies the pattern of its advertizing process throught the analysis of the advertizing materials.

Concludes that the Brazilian editorial industry concerning to elementary education has a diversified production, ofering a variety of materials, tipical of the information environmental of the contemporany society. The analysis of the adverstizing material shows some deficiencies concerning the information needed for the selection of the material.

\section{Keywords}

Information sources; Information resources; Information for education

\section{Bernadete Santos Campello}

Professora da Escola de Biblioteconomia da UFMG, mestre em biblioteconomia pelo Curso de Pós-graduação em Administração de Bibliotecas da Escola de Biblioteconomia da UFMG.

e-mail: Campello@eb.ufmg.br e

\section{Paulo da Terra Caldeira}

Professor da Escola de Biblioteconomia da UFMG, mestre em biblioteconomia pelo Curso de Mestrado em Ciência da Informação do IBICT/UFRJ.

e-mail: terra@eb.ufug.br

\section{Aparecida Imaculada Bedeti da Silva Manuel Valente Mangue}

Alunos bolsistas de iniciação científica (FAPEMIG e CNPq).

Endereço: Escola de Biblioteconomia da UFMG. Caixa Postal 1606 CEP: 30161-970 Belo Horizonte MG Fone: (031) 499-5250 FAX: (031) 499-5200 


\section{ANEXO 1}

\section{MEIOS UTILIZADOS PARA IDENTIFICAÇÃO DOS PRODUTORES}

\section{PUBLICAÇÕES}

Catálogo dos Editores Brasileiros. Publicado pela Fundação Biblioteca Nacional, fornecendo, além do nome, o endereço e telefone da instituição;

Who's who; Catálogo de Empresas Associadas à Câmara Brasileira do Livro, fornecendo dados sobre editoras, distribuidoras e livrarias. Nome, endereço, telefone, nome da pessoa para contato, categoria e área de atuação. Incluindo descrição da sua linha editorial;

Catálogo Lecionare. Publicação anual da Forma Editora Ltda, reunindo as principais novidades em software educativos, livros didáticos e literatura. Inclui também o nome e o endereço completo das instituições.

Guia de Vídeos da Editora Nova Cultural, fornecendo uma relação de distribuidoras de vídeo em todo o país, com o endereço completo de cada uma delas.

Um trabalho sobre distribuidoras e produtoras de fitas de vídeo no Brasil:

CARVALHO, Everardo F. de. Distribuidoras e produtoras de fitas de vídeo no Brasil. Belo Horizonte: Escola de Biblioteconomia/UFMG, 1989. (Trabalho de aluno da Pós-graduação).

Boletins da Fundação Nacional do Livro Infantil e Juvenil (FNLIJ), contendo informações sobre feiras de livro, premiações, congressos, eventos em geral, entrevistas etc;

Publicações especializadas sobre produtos eletrônicos (Revista Exame, Pc Word, Cadernos de Informática dos principais jornais do país etc). Tais publicações auxiliaram na identificação dos software educativos.

Cadernos Infantis dos principais jornais do país

Material do $3^{\circ}$ Congresso Internacional de Educação (Educator' 96), realizado em São Paulo em 1996.

VISITAS

Foram realizadas visitas às seguintes instituições:

- bibliotecas infanto-juvenis (4), onde foram identificadas, por intermédio de catálogos e, em alguns casos, por meio dos próprios livros, os endereços das editoras;

- Câmara Mineira do Livro, onde se obteve a lista dos associados; nela foram identificadas algumas editoras;

- distribuidoras de livros e bancas de jornais, que forneceram nome e endereço de organizações que publicam revistas em quadrinhos e outros materiais normalmente comercializados em bancas;

- vídeo locadoras: forneceram nome e endereço das distribuidoras de fitas de vídeo;

- Centro de Referência do Professor, da Secretaria de Estado da Educação/MG, que forneceu a lista das editoras das quais são adquiridos materias para as bibliotecas estaduais;

- 14 a Bienal Internacional do Livro, realizada em São Paulo, em setembro de 1996, quando a coordenadora da pesquisa esteve em todos os estandes de interesse para a pesquisa e obteve material de divulgação de diversas editoras.

- Feira Cantinhos de Leitura, realizada em Belo Horizonte, em maio de 1997.

Tentou-se localizar as produtoras de vídeo por meio de questionário enviado a 119 distribuidoras de vídeo no Brasil, identificadas no Guia de Vídeos, da Editora Nova Cultural, e em listas telefônicas. Entretanto, o retorno dos questionários foi praticamente nulo, devido a um número significativo de correspondência devolvida, com indicação de mudança de endereço. Assim sendo, a pesquisa não contou com dados a esse respeito. 


\section{ANEXO 2 - QUESTIONÁRIO}

\section{1) Identificacão}

Nome da Empresa:

Local da Sede (Cidade/Estado):

Filiais (Cidade/Estado):

Data de início das atividades (Ano):

$N^{\circ}$ de todos os titulos editados/produzidos pela empresa em 1995:

Tiragem média desses titulos:

1.1) Edita/produz materiais, recursos informacionais, para o ensino de $1^{\circ}$ grau (literatura infantil, livros didáticos, software educativo,vídeo, disquete, $C D$-ROM etc.)
( ) $\operatorname{Sim}$
( ) Não

\section{2) Distribuição}

Como é o sistema de distribuição
( ) Distribuidora
$\mathrm{N}^{\circ}$ de distribuidoras
( ) Loja própria
$\mathrm{N}^{\circ}$ de lojas
( ) Vendedores próprios
$\mathrm{N}^{\circ}$ de vendedores

\section{3) Divulgação}

Como é a forma de divulgação?

( ) Catálogo

( ) Folder (impresso de uma única folha)

( ) Publicidade na mídia

( ) Feiras

3.1) A quem é enviado o catálogo?

( ) A distribuidoras

() A escolas

( ) A pessoas físicas

( ) A outra(s) instituições (Indicar)
( ) Congressos/Seminários

( ) Visita de Promotores

( ) Outro(s).(Indicar).

Com que frequência o catálogo é atualizado?
() Anualmente
( ) Semestralmente
( ) Mensalmente
( ) Outro. (Indicar)

Com que frequência o folder é atualizado?
() Anualmente
( ) Semestralmente
() Mensalmente
( ) Outro. (Indicar) 


\section{3) Como é feita a publicidade?}
( ) Jornal
( ) Outdoor
( ) Revista
( ) Televisão
( ) Rádio
( ) Outro(s) (Indicar)

3.4) Qual o âmbito da divulgação?
( ) São Paulo
( ) Rio de Janeiro
( ) Todo o Brasil

Outro(s). (Indicar)

4) Há planos para produção de material em $C D-R O M$ ou disquete?
( ) Já produzimos
( ) $\mathrm{Sim}$
( ) Não
Para quando (ano)

5) Inclua as observações que julgar necessárias: 